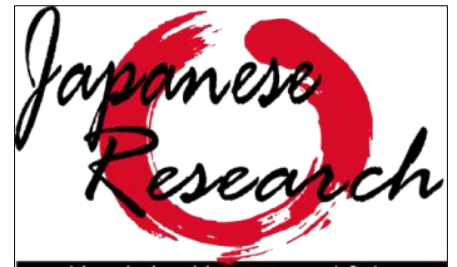

on Linguistics, Literature and Culture
Japanese Research on Linguistics, Literature, and Culture Vol. 2 No. 1 Nov. 2019, p., 16-35 ISSN Online: 2655-4836

DOI: $10.33633 /$ jr.vlil.3348

http://publikasi.dinus.ac.id/index.php/jrllc/article/view/3348/1820 japanese.research@fib.dinus.ac.id

Published by Universitas Dian Nuswantoro, Semarang

\title{
Deiksis Bahasa Jepang dalam Studi Linguistik Pragmatik
}

\author{
Akhmad Saifudin \\ Universitas Dian Nuswantoro \\ akhmad.saifudin@dsn.dinus.ac.id
}

Article History: Submitted date 2019-10-28; Accepted date 2019-11-3; Published date 2019-11-20

\begin{abstract}
This paper examines the use of deixis in Japanese. Deixis is one of the language phenomena whose frequency of occurrence in speech activities is many and varied. Basically, there are three types of deixis, namely person, spatial, and time. There are now two additional deixis, social deixis and discourse. This paper attempts to recognize the characteristics of Japanese deixis. With the aim that the data obtained is more varied, the data of this paper does not come from one source, but from various sources on the internet. By using the Pragmatic approach and theories about deixis (Fillmore, 1975; Hasegawa, 2012; Kuno \& Kaburaki, 1977; Levinson, 1983; Lyons, 1977; Wetzel, 1988), this paper concludes that social and psychological contexts play a significant role very important in the use of Japanese language deixis. Social deixis and emphatic are central in Japanese deixis studies.
\end{abstract}

Keywords: deixis, pragmatic, social deixis, emphatic deixis

\begin{abstract}
Abstrak
Tulisan ini mengkaji penggunaan deiksis dalam bahasa Jepang. Deiksis adalah salah satu fenomena bahasa yang frekuensi kemunculannya dalam aktifitas pertuturan banyak dan beragam variasinya. Pada dasarnya, jenis deiksis ada tiga, yakni orang, tempat, dan waktu. Saat ini sudah ada tambahan dua deiksis yakni deiksis sosial dan wacana. Tulisan ini mencoba mengenali karakteristik deiksis bahasa Jepang. Dengan tujuan agar data yang dperoleh lebih bervariatif, data tulisan ini tidak berasal dari satu sumber, melainkan dari berbagai sumber di internet. Dengan menggunakan ancangan Pragmatik dan teoriteori tentang deiksis (Fillmore, 1975; Hasegawa, 2012; Kuno \& Kaburaki, 1977; Levinson, 1983; Lyons, 1977; Wetzel, 1988), tulisan ini menghasilkan simpulan bahwa konteks sosial dan psikologis memegang peran yang sangat penting dalam penggunaan deiksis bahasa Jepan. Deiksis sosial dan empati menjadi sentral dalam kajian deiksis bahasa Jepang.
\end{abstract}

Kata Kunci: deiksis, pragmatik, deiksis sosial, deiksis empati 


\section{Pendahuluan}

Dalam bahasa Jepang deiksis disebut chokuji (直示'indikasi langsung') atau daikusisu (ダ イクシス 'kata serapan dari deixis'). Menurut Lyons (1977: 636) deiksis adalah

By deixis is meant the location and identification of persons, objects, events, processes and activities being talked about, or referred to, in relation to the spacio-temporal context created and sustained by the act of utterance and the participation in it, typically, of a single speaker and at least one addressee.

Kemudian menurut Levinson, deiksis adalah bidang penting yang dipelajari dalam pragmatik, semantik, dan linguistik. Deiksis mengacu pada fenomena yang memerlukan informasi kontekstual untuk memahami makna kata-kata dan frasa tertentu dalam tuturan. Kata atau frasa yang memerlukan informasi kontekstual untuk menyampaikan makna itulah yang disebut deiksis (1983: 54). Kata-kata seperti saya, di sini, dan kemarin adalah contoh kata-kata yang memerlukan informasi kontekstual untuk memahaminya. Diperlukan pemahaman konteks tentang siapa yang bertutur, di mana dan kapan tuturan tersebut dituturkan. Sebagai contoh

untuk memaknai tuturan "Nanti saya akan pergi ke sana." harus diketahui kapan tuturan dituturkan, siapa yang bertutur, dan di mana dituturkan.

Dari hasil studi literatur, saya menemukan tiga jenis deiksis, yakni deiksis orang (saya, anda, kami), spasial/tempat (ini, itu, di sini, di sana), dan deiksis temporal/waktu (sekarang, hari ini, kemarin). Sebagai tambahannya, Levinson (1983), mengikuti Lyons (Leech, 2014) dan Fillmore (1975), menambahkan dua kategori deiksis lainnya, yakni deiksis sosial yang mencakup pengkodean perbedaan sosial yang relatif terhadap peran-peserta, khususnya aspek dari hubungan sosial yang terjadi antara penutur dan mitra tutur atau penutur dan beberapa referensi, dan deiksis wacana yang melibatkan pengkodean referensi ke bagian wacana yang sedang berlangsung di mana ucapan itu berada. Bagi Levinson (1983: 64), deiksis diorganisasikan secara egosentris, dengan pusat deiktik merupakan titik referensi sehubungan dengan ekspresi deiksis yang ditafsirkan. Misalnya, dalam tuturan seperti saya di sini sekarang, penutur, lokasi aktual, dan waktu aktual tuturan menjadi pusat deiksis. Yang harus digarisbawahi adalah bahwa Istilah pusat deiksis harus berhubungan dengan situasi di mana 
tepatnya titik tuturan itu dibuat atau teks ditulis, dengan kata lain harus berhubungan dengan posisi dari mana istilah deiksis dipahami.

Apa yang sudah dibahas para ahli tersebut, lebih banyak menitik beratkan pada konteks fisik, dalam arti lebih melihat pada identitas siapa partisipan pertuturan, di mana dan kapan pertuturan berlangsung. Ataupun dalam hal deiksis wacana yang melihat acuan pada kata-kata atau pun frasa yang ada pada bagian sebelum atau sesudah teks. Padahal, dalam realitasnya pilihan deiksis yang digunakan juga bergantung pada konteks psikologis. Masalah jarak tempat, waktu, dan hubungan juga bergantung pada konteks psikologis. Sebagai contoh, jika dua orang yang secara fisik disebut 'teman' dikarenakan mempunyai lingkungan yang sama dan sering berinterasi, terkadang membuat istilah deiksis orang untuk menyebut orang kedua dengan sebutan yang berbeda hanya karena situasi emosionalnya. Dalam situasi normal menyebut 'kamu' atau 'bajingan' ketika dalam situasi marah atau bercanda . Inilah yang akan dikaji dalam tulisan ini untuk melengkapi kajian deiksis yang selama ini sudah ada, yang lebih memfokuskan kepada acuan-acuan fisik.

\subsection{Deiksis: Kajian Semantik atau Pragmatik?}

Kajian Semantik dan Pragmatik memang seringkali bersinggungan dan dianggap tumpang tindih. Kedua bidang ini sama-sama mengkaji makna. Semantik mengkaji makna tuturan (atau lebih tepatnya kalimat) berdasarkan kepada "pengetahuan bahasa" yang mencakup tata bahasa dan relasi makna kata atau bahasa . Sementara Pragmatik mengkaji makna tuturan dengan tidak hanya tergantung pada pengetahuan linguistik, tetapi juga tergantung pada pengetahuan tentang konteks tuturan, pengetahuan tentang status partisipan yang terlibat, seperti informasi sosial yang dikodekan dengan berbagai ekspresi mengenai status sosial dan hubungan keakraban, maksud pembicara, tempat, dan waktu ketika dituturkan. Singkatnya pragmatik sangat tergantung pada konteks tuturan. Konteks tuturan sendiri, pada dasarnya meliputi konteks linguistik, fisik, psikologis, sosial, dan konteks pengetahuan bersama, yang jika dirangkum atau disederhanakan dapat dikatakan pragmatik membutuhkan konteks pengetahuan bersama untuk bertutur dan memaknai tuturan (Saifudin, 2018). Dengan demikian dapat dikatakan bahwa makna dalam Pragmatik sifatnya tidak tetap 
(dinamis) karena tidak tergantung pada bentuk kata atau frasa yang digunakan. Satu kata yang sama dapat bermakna lain jika konteksnya berbeda. Dalam Semantik makna lebih stabil karena tidak tergantung pada konteks. Makna Semantik dibangun dari tata bahasa serta peran unsurunsur pembentuk kalimat.

Nah, bagaimana dengan deiksis? Apabila kita melihat konsep dari deiksis, maka secara logis kita dapat memasukkannya ke dalam bidang Pragmatik, mengingat untuk memaknai ekspresi deiksis selalu dibutuhkan konteks.

\subsection{Jenis-Jenis Deiksis}

Seperti yang sudah dipaparkan sebelumnya, saat ini kita mengenal lima jenis deiksis, yakni deiksis orang, tempat, waktu, sosial, dan wacana.

1. Deiksis orang

Deiksis orang berkenaan dengan peran peserta dalam pertututuran. Pada umumnya deiksis ini menggunakan kata ganti persona sebagai ekspresinya, kategori orang pertama adalah referensi pembicara untuk dirinya sendiri, orang kedua untuk orang yang diajak bicara, dan orang ketiga untuk orang yang dibicarakan yang tidak terlibat sebagai peserta tutur langsung. Berikut ini adalah contoh deiksis orang.

(1) Dia! Ya, dia pencurinya. Dia itu pencurinya!

(2) Saya sudah menyampaikan kepadanya untuk segera mengembalikan uangnya.

2. Deiksis tempat

Deiksis ini berkaitan dengan lokasi spasial relatif terhadap lokasi peserta saat pertuturan. Lokasi secara garis besar dibedakan atas konsep proksimal (dekat dengan penutur) dan distal (tidak dekat; kadang-kadang dekat dengan mitra tutur). Pada umumnya deiksis tempat berujud kata keterangan tempat (di sini, di sana) dan kata ganti demonstratif (ini, itu). Sebagai contoh adalah sebagai berikut.

(3) Saya sudah pernah pergi ke sana.

(4) Itu adalah tempat yang sangat dingin.

3. Deiksis waktu

Deiksis waktu berhubungan dengan pengkodean penunjuk waktu dan rentang waktu relatif terhadap waktu pada saat pertuturan dituturkan. Secara gramatikal biasanya ditunjukkan 
dengan kata ganti keterangan waktu seperti sekarang, tadi, minggu ini, bulan depan, dan lainlain. Contoh:

(5) Kemarin saya terlambat. Hari ini juga terlambat. Mudah-mudahan besok tidak terlambat lagi.

(6) Sudah dua minggu saya tidak bertemu dengannya.

4. Deiksis wacana

Deiksis ini juga dapat juga disebut sebagai deiksis tekstual karena rujukannya berada dalam teks yang sama ketika sedang berlangsung. Rujukannya dapat berupa anaforis (merujuk kepada bagian sebelumnya) dan kataforis (merujuk kepada bagian setelahnya). Contoh deiksis wacana adalah sebagai berikut.

(7) Inilah yang akan kita bahas di dalam rapat ini.

(8) Joko tidak bisa membayar tiket kereta, dompetnya ketinggalan.

5. Deiksis sosial

Deiksis sosial menyangkut pengkodean perbedaan sosial yang relatif terhadap peran partisipan, khususnya aspek hubungan sosial yang terjadi antara penutur dan mitra tutur atau pembicara dan beberapa referensi (Levinson, 1983: 63). Pada umumnya berkaitan erat dengan kesantunan bahasa (politeness). Ungkapan deiksis dapat berupa kata ganti orang, kata benda, kata kerja yang merefleksikan hubungan sosial relatif antarpeserta tutur. Contohnya adalah sebagai berikut.

(9) Saya mohon Bapak berkenan hadir dalam pertemuan nanti.

(10) Beliau adalah satu-satunya orang yang berhasil mendamaikannya.

\subsection{Metode Penelitian}

Penelitian ini menggunakan data berupa teks atau tuturan yang di dalamnya terdapat ungkapan deiksis. Data diperoleh dari teks-teks yang terdapat di internet dengan tujuan untuk dapat memperoleh variasi yang cukup tentang penggunaan dan ragam deiksis. Dengan menggunakan ancangan pragmatik data dianalisis berdasarkan teori konteks (Saifudin, 2018) dan deiksis (Fillmore, 1975; Hasegawa, 2012; Kuno \& Kaburaki, 1977; Levinson, 1983; Lyons, 1977; Wetzel, 1988). 


\section{Hasil dan Pembahasan}

\subsection{Karakteristik Bahasa Jepang}

Bahasa Jepang adalah bahasa yang mempunyai struktur S-O-V (subjek-objek-verba). Menurut Shibatani (1990: 257), bahasa Jepang mempunyai struktur S-O-V yang ideal, dalam arti bahwa word order "dependent-head" secara konsisten dipertahankan sehubungan dengan semua jenis konstituen. Beberapa aturan dasar dalam struktur bahasa Jepang adalah sebagai berikut.

(a) hubungan nominal diekspresikan oleh partikel postpositional;

Taroo ga Hanako ni hon o yatta.

NOM DAT buku ACC memberi

'Taro memberi buku kepada Hanako.'

(b) kata sifat demonstratif, angka, dan deskriptif mendahului head (kata benda) dalam

urutannya;

sono san-nin no ookina otoko

itu tiga orang besar pria

'tiga pria besar itu'

(c) kata benda genitif mendahului head dimiliki;

Taro no hon

GEN buku

'buku (milik) Taro'

(d) klausa relatif mendahului nomina yang dimodifikasi;

$\begin{array}{cc}\text { [Taroo ga katta] } & \text { hon } \\ \text { NOM membeli (PST) } & \text { buku }\end{array}$

'buku yang dibeli Taro'

(e) kata benda nama diri (proper noun) mendahului kata benda umum (common noun);

Taro ojisan

Paman

'paman Taro'

(f) kata keterangan mendahului kata kerja yang dimodifikasi;

hijoni hayaku hashiru

sangat cepat lari

'lari sangat cepat' 
(g) pembantu mengikuti kata kerja utama;

$$
\begin{aligned}
& \text { ik - e - nai } \\
& \text { pergi - dapat }- \text { tidak } \\
& \text { 'tidak bisa pergi' }
\end{aligned}
$$

(h) ekspresi komparatif menggunakan penanda standar urutan dari kata sifat pembanding.

$$
\begin{aligned}
& \text { Taro yori kashikoi } \\
& \text { dari pandai } \\
& \text { 'lebih pandai dari Taro' }
\end{aligned}
$$

Karakter lain bahasa Jepang yang penting adalah adanya perbedaan yang jelas menyangkut dunia perolehan informasi dan distribusi pengetahuan. Dalam bahasa Jepang dibedakan antara pengetahuan yang diakses langsung oleh penutur dan yang tidak. Seperti dalam tuturan:

$$
\text { watashi ha sushi ga hoshii. }
$$

Saya (1) TOP sushi NOM ingin.

'saya ingin sushi'

$$
\begin{aligned}
& \text { Tanaka ha sushi ga hoshigatteiru } \\
& \text { TOP NOM ingin EVID } \\
& \text { "sepertinya Tanaka menginginkan sushi' }
\end{aligned}
$$

Masalah rasa atau keinginan ataupun predikat yang sifatnya psikologis adalah otoritas dari penutur bagi dirinya. Penutur tidak boleh menyatakan perasaan orang lain karena ia tidak mempunyai akses langsung dan tidak berhak atau tidak mempunyai otoritas untuk menuturkannya. Untuk menyatakan perasaan atau kondisi psikologis orang lain harus menggunakan bentuk yang mengindikasikan ketidaklangsungan akses, seperti garu (tandatandanya), rashii (nampaknya), ataupun soo (katanya).

Karakter berikutnya yang juga sangat penting adalah bahasa Jepang sangat memperhatikan konteks, terutama konteks sosial (dan budaya). Dalam hal ini sangat berhubungan dengan kesantunan bahasa (politeness). Bahasa Jepang mempunyai sistem politeness yang disebut keigo. Keigo ini mengatur bagaimana orang Jepang menggunakan bahasa dalam berinteraksi dengan orang lain. Keigo sangat berpengaruh dalam penggunaan 
pilihan kata/frasa, baik nomina, ajektiva, ataupun verba. Penggunaan ragam bahasa diatur berdasarkan aturan sosial dan aturan kebahasaan/keigo (Saifudin, 2010). Sebagai contoh untuk mengatakan "I am a student" atau "Saya (adalah) siswa" dalam bahasa Jepang dapat bervariasi tergantung konteksnya.

(13.a) Watashi ha gakusei desu.

Saya TOP siswa COP/POL

(13.b) Boku ha gakusei da.

Saya (MASC) TOP siswa COP

(13.c) Watakushi ha gakusei de gozaimas-u.

Saya (HUM) TOP siswa COP/HUM - NPST

I (bahasa Inggris) atau saya (bahasa Indonesia), dapat diterjemahkan ke dalam bahasa Jepang dengan berbagai variasi tergantung jenis kelamin dan formalitasnya. Sementara am (to be) diterjemahkan dengan copula dengan variasi dari ragam informal da sampai dengan ragam sopan merendah de gozaimasu. Akan menjadi tidak berterima jika seseorang menuturkan boku ha gakusei desu, karena kata ganti boku seharusnya digunakan dalam situasi tidak formal.

Orang Jepang juga terikat pada konsep budaya uchi-soto dan joge-kankei. Uchi berarti "di dalam, internal, privat", soto berarti "di luar, eksternal, publik" (Lebra \& Lebra, 1976; Saifudin, 2005). Yang disebut uchi adalah dirinya sendiri, anggota keluarga, kelompok, sekolah, perusahaan, maupun negaranya, dan yang disebut soto adalah orang-orang yang berada di luar kelompoknya atau orang asing. Adanya dikotomi uchi dan soto berpengaruh pada perilaku interaksi orang Jepang, termasuk tentu saja bahasa yang dipergunakan. Ketika berinteraksi dengan uchi, maka perilaku yang nampak adalah santai, intim, dan tidak berjarak. Sementara perilaku dengan soto cenderung formal, sopan, dan berjarak. Konsep yang kedua adalah jogekankei 'hubungan atas-bawah', yakni konsep masyarakat yang mengatur anggotanya berdasarkan perbedaan "kualitas" baik dari sisi usia, senioritas, jabatan, dan lain-lain. Di dalam konsep ini orang harus lebih menghormati orang lain yang mempunyai kualitas yang lebih tinggi, usia yang lebih muda harus lebih menghormati orang yang lebih tua, yunior harus hormat kepada seniornya, bawahan kepada atasannya, dan seterusnya. Kedua konsep budaya Jepang inilah yang mendasari perilaku interaksi orang Jepang, termasuk dalam hal penggunaan bahasa. Dengan kata lain, keigo yang mengatur penggunaan bahasa hormat 'politeness' didasari 
atas kedua konsep ini. Orang Jepang tidak bisa secara sembarangan menggunakan kata sapaan kepada mitra tuturnya, sudah ada pilihan-pilihan bahasa yang harus digunakan sesuai peran sosial penutur dan mitra tutur atau partisipan lainnya.

Lebih lanjut, konsep uchi-soto dan joge-kankei juga berpengaruh pada apa yang disebut empati dalam bahasa. Empati adalah pengidentifikasian seseorang (penutur) terhadap orang lain yang berpartisipasi dalam pertuturan (Kuno \& Kaburaki, 1977; Wetzel, 1988). Dalam The SIL online Glossary of linguistic disebutkan bahwa Empathetic deixis is the metaphorical use of deictic forms to indicate emotional or other psychological "distance" or "proximity" between a speaker and a referent (Irgens, 2017: 218). Singkatnya empati adalah bagaimana seorang penutur menyiratkan kedekatan emosionalnya terhadap partisipan pertuturan. Sehubungan dengan masalah empati ini, Kuno mengusulkan beberapa aturan yang disebut "Prinsip empati" (Kuno \& Kaburaki, 1977: 5). Dalam prinsip ini disebutkan:

1. Dalam satu kalimat fokus empati penutur tidak bisa lebih dari satu.

*Mary's husband hit his wife.

'Suami Mary memukul istrinya'

Kalimat ini janggal karena penutur menunjukkan empati kepada Mary dengan menyebut suaminya sebagai suami Mary sementara secara bersamaan mengekspresikan empati dengan John dengan menyebut Mary sebagai istrinya.

2. Struktur Permukaan Hierarki Empati: Sulit untuk berempati pada referensi agentif dengan mengesampingkan turunan pasif dalam kalimat.

Subject > Object > ... > Passive by Agentive

*John's wife was hit by him

3. Hierarki empati partisipan pertuturan: Tidak dimungkinkan bagi penutur untuk berempati dengan orang lain dengan mengesampingkan dirinya sendiri.

Speaker/Hearer > Third Person atau lebih tepatnya uchi > soto

*John was hit by me

\subsection{Deiksis dalam Bahasa Jepang}

Dengan melihat karakteristik bahasa Jepang yang telah dipaparkan sebelumnya, maka pembagian lima jenis deiksis secara umum tidak dapat begitu saja dapat diberlakukan dalam 
kasus bahasa Jepang. Masing-masing tidak dapat berdiri sendiri karena setiap jenis deiksis harus melibatkan karakter bahasa Jepang yang berpusat pada faktor sosial (dan budaya) Jepang. Dengan demikian deiksis sosial menjadi pusat dari pemahaman atau penggunaan deiksis bahasa Jepang, lebih khusus lagi adalah faktor empati dalam bahasa Jepang.

\section{Deiksis orang}

Seperti dalam (13 a, b, dan c) kita dapat melihat bahwa deiksis orang tidak semata-mata hanya berdasarkan penutur, mitra tutur, dan partisipan lain yang terlibat atau dibicarakan. Ketiga hal ini pada umumnya memang menjadi dasar penggunaan deiksis orang, yang kemudian diwujudkan melalui penggunaan kata ganti orang (dalam bahasa Jepang disebut daimeishi). Wujud leksikal kata ganti orang dalam bahasa Jepang di antaranya adalah sebagai berikut (Saifudin, 2006).

Tabel 1. Kata Ganti Orang dalam Bahasa Jepang

\begin{tabular}{lc}
\hline \multicolumn{1}{c}{ Tunggal } & Orang pertama \\
\hline Watakushi (humble) & Wamak \\
\hline watashi (formal) & Wareware \\
\hline Atashi (informal, feminine speaker) & Warera \\
\hline Boku (masculine speaker) & \\
\hline Ore (informal, masculine speaker) & \\
\hline Uchi (informal, feminine speaker) & \\
\hline Washi (old masculine speaker) & \\
\hline Jibun (emphatic, 'myself') & Orang kedua \\
\hline Otaku (formal) & \\
\hline Anata (formal) & Anata gata \\
\hline Anta (informal, feminine speaker) \\
\hline Kimi (masculine speaker, lower status addressee) \\
\hline
\end{tabular}


Omae (informal, masculine speaker, equal or

lower status addressee)

Jibun (emphatic, 'yourself')

\section{Orang ketiga}

\section{Kanojo}

Kare

Karera

demonstrative + hito

Ano hito tachi

demonstrative prefix + -itsu: koitsu, soitsu, aitsu

(vulgar)

Penggunaan kata ganti seperti tercantum dalam tabel 1 sangat tergantung pada konteks, utamanya adalah konteks sosial dan psikologis, yang biasanya juga melibatkan penggunaan predikat atau verba dalam tuturannya. Tuturan dengan predikat sopan dan atau formal tidak memungkinkan menggunakan ungkapan deiksis orang yang tidak sopan apalagi vulgar.

Sebagai tambahan, meskipun bahasa Jepang menyediakan banyak pilihan kata ganti, dalam realitas penggunaannya justru sering dilesapkan. Ketika seseorang bertutur dengan mitra tuturnya, sangat jarang digunakan secara eksplisit kata ganti orang pertama sebagai penutur dan kata ganti orang kedua sebagai mitra tutur. Sebagai contoh:

(14) Kekkonshiki de nani wo ageta?

Resepsi pernikahan pada apa ACC memberi PST Q

'Apa yang (kamu) hadiahkan (kepada dia/mereka) pada resepsi pernikahannya?'

Pada tuturan (14) semua partisipan dilesapkan, dan itu adalah sesuatu yang berterima dan bahkan lebih natural dalam pertuturan bahasa Jepang. Dengan melihat predikat tuturan tersebut sudah dapat diketahui bahwa penutur dan mitra tutur sederajat dan mempunyai hubungan yang dekat (uchi), sementara hubungan dengan orang yang dibicarakan lebih jauh jaraknya (soto). Verba ageta merupakan ragam Nonpoliteness. Penutur mengidentifikasikan dirinya cenderung kepada mitra tuturnya dibanding orang yang dibicarakan (empati lebih kepada mitra tutur atau orang kedua). 
Apa yang dapat disimpulkan dari fenomena deiksis orang di sini adalah keberadaan deiksis orang dalam bahasa Jepang harus melibatkan deiksis sosial dan deiksis empati. Penggunaan deiksis orang tanpa melihat keduanya akan berpotensi menjadi tuturan yang tidak berterima.

\section{Deiksis tempat}

Seperti yang sudah dipaparkan dalam uraian sebelumnya, wujud deiksis tempat adalah keterangan tempat dan kata ganti demonstratif. Dalam bahasa Jepang keterangan tempat dapat diwujudkan dalam kata ganti koko/kochira, soko/sochira, asoko/achira dan doko/dochira untuk kata tanyanya, sementara untuk menggambarkan kata ganti demonstratif dengan menggunakan kore (pronominal), kono (adnominal), sore (pronominal), sono (adnominal); serta are (pronominal), ano (adnominal). Penggunaan chira menunjukkan ragam yang lebih sopan, sehingga dalam penggunaan deiksis tempat dengan adanya ragam sopan akan dipengaruhi juga oleh deiksis sosial.

Apabila kita lihat penggunaan ungkapan deiksis dalam bahasa Jepang ditunjukkan dengan awalan ko, so dan a. Adapun penggunaannya dapat diidentifikasi dengan dua model, yakni model jarak (distance model)dan wilayah (territory model). Konsep model jarak adalah

jika penutur dan mitra tuturnya secara fisik menghadap ke arah yang sama , awalan ko jika objek dekat dengan mereka, so jika agak jauh, dan a jika jauh. Sementara model wilayah jika penutur dan mitra tuturnya saling berhadapan dan penggunaan ko jika objek dekat dengan penutur, so dekat dengan mitra tutur, dan a jika jauh dari keduanya (Wetzel, 1988).

(15) Sore ha nan desu ka? Itu TOP apa COP Q 'Apakah itu?'

Dalam (15) jika dilihat dari model jarak, objeknya berada agak jauh dari penutur dan mitra tuturnya, dan jika dilihat dari model wilayah maka objeknya berada di dekat mitra tuturnya.

Lebih jauh tentang penggunaan ko, so, $a$ ini, Kuno (1972) menyatakan bahwa ko hanya dapat digunakan secara deiksis, namun so dan a dapat digunakan baik secara deiksis maupun anaforis (dalam Hasegawa, 2012: 44). Dalam hal ini Kuno memang membedakan antara deiksis 
dan anafora, walaupun banyak di antara ahli linguistik menyamakan keduanya. Penggunaan deiksis adalah secara fisik dapat ditunjuk dan penggunaan anafora berada dalam wacana (deiksis wacana/tekstual). Untuk penggunaan secara deiksis, pendapat Kuno sejalan dengan model wilayah, sementara untuk penggunaan anaforis dapat dijelaskan sebagai berikut.

\section{Penggunaan so:}

- jika penutur tidak mengetahui dengan jelas rujukannya atau penutur tidak mempunyai pengetahuan langsung (hanya indirect knowledge); atau

- jika penutur mempunyai rujukan yang jelas (mempunyai direct knowledge), tetapi mengasumsikan mitra tuturnya tidak mengetahuinya.

Sementara penggunaan $a$ adalah:

- jika penutur meyakini bahwa ia mempunyai rujukan yang jelas (direct knowledge) dan meyakini juga kalau mitra tuturnya mempunyai kondisi yang sama.

Sebagai contoh:

A: senshuu, Susukino he itta yo.

B: sou ka. Soko (asoko*) ha donna tokoro?

'A: minggu lalu, aku ke Susukino Iho.'

'B: o ya. Tempatnya seperti apa di sana?

Penggunaan asoko akan tidak berterima karena penutur tidak mengetahui dengan baik tempat yang bernama Susukino. Akan tetapi jika B merespon dengan "kireina tokoro ne, asoko." (tempat yang indah ya, di sana.), maka yang digunakan adalah asoko, karena keduanya mempunyai referensi yang baik terhadap tempat yang dibicarakan.

(17) Sono hito dare!

'orang itu siapa!"

Dalam (17), tuturan tersebut dituturkan kepada kekasihnya ketika mendatangi kekasihnya dan menjumpainya sedang berbicara dengan perempuan lain. la menggunakan deiksis sono dan bukan kono, sekalipun orang yang dituju berada dekat. Di sini sekali lagi adalah masalah empati, atau masalah emosional. Penggunaan sudah bukan masalah letak secara fisik, namun lebih secara emosional. Secara fisik dekat, tetapi penutur sengaja menjauhkan karena rasa tidak sukanya kepada orang yang dimaksud. 
Dalam bahasa Jepang, deiksis tempat juga dapat terefleksikan dari predikat atau verba, yakni melalui apa yang disebut deiksis pergerakan (motion deixis). Deiksis ini merupakan penunjuk perpindahan dari satu tempat menuju ke tempat lain. Verba yang digunakan adalah $i k u$ 'pergi' dan kuru 'datang' (beserta verba bantu te iku dan te kuru). Titik sentral perpindahan adalah lokasi pertuturan yang mana verba $i k u$ adalah perpindahan menjauh dari lokasi pertuturan dan kuru mendekati lokasi pertuturan. Secara semantik iku berorientasi kepada sumber (source-oriented) dan kuru kepada tujuan (goal-oriented).

$$
\begin{aligned}
& \text { Asoko he iku. (*asoko he kuru) } \\
& \text { Sana ke pergi NPST datang } \\
& \text { 'pergi ke sana' (*datang ke sana) }
\end{aligned}
$$

Dalam (18) verba yang digunakan untuk menyatakan perpindahan dari lokasi pertuturan ke tempat lain (asoko) harus iku karena menjauh dari lokasi pertuturan dan orientasinya adalah sumber lokasi pertuturan.

(19) Kino Taroga anata no uchi ni itta toki, anata inakatta sou ne. Kemarin NOM kamu GEN rumah ke pergi PST waktu, kamu ada NEG PST katanya FP. 'Kemarin pada waktu Taro d ke rumahmu, katanya kamu gak ada di rumah ya.'

Dalam (19) verba yang digunakan juga harus iku (itta adalah bentuk lampau) karena lokasi pertuturan tidak berada di rumah mitra tutur. Dalam bahasa yang lain seperti bahasa Indonesia penggunaan verba datang mungkin dapat berterima, namun tidak dalam bahasa Jepang.

Umi ni itte kuru ne. Laut ke pergi datang (AUX) FP

'(Saya) pergi ke pantai ya.'

Penggunaan verba deiksis itte (bentuk sambung dari iku 'pergi') digunakan karena menjauh dari lokasi pertuturan dan penggunaan verba bantu kuru 'datang' menunjukkan bahwa setelah pergi ke pantai, penutur akan kembali lagi ke tempat pertuturan.

(21) Tomodachiga omiyage wo motte kita.

Teman NOM oleh-oleh ACC membawa datang (AUX) PST

'Teman datang membawa oleh-oleh.'

Seperti dalam (20) penggunaan verba bantu te kuru menunjukkan aktivitas yang pada akhirnya dibawa menuju lokasi pertuturan, sementara penggunaan verba bantu iku adalah sebaliknya, menjauh dari lokasi pertuturan. 
Deiksis waktu

Dalam bahasa Jepang deiksis waktu digunakan untuk mengkodekan penunjuk waktu dan rentang waktu relatif terhadap waktu pada saat pertuturan dituturkan. Realisasinya dapat berupa keterangan waktu dan predikat atau verba yang merefleksikan waktu aktivitas atau peristiwa (tenses).

(23) Kesa pan wo tabeta.

Tadi pagi roti ACC makan PST.

'Tadi pagi (saya) makan roti.'

Dalam (23) deiksis waktu dapat diidentifikasi melalui kata keterangan kesa dan bentuk verba lampau tabeta (bentuk lampau dari taberu 'makan').

Deiksis waktu juga dapat direpresentasikan melalui verba bantu te iku dan te kuru. Kalau dalam deiksis tempat kedua verba ini menunjukkan pergerakan/perpindahan tempat, dalam deiksis waktu menunjukkan pergerakan/aliran waktu dari sudut pandang penutur. Lebih jelasnya te kuru menyatakan sesuatu perubahan datang/bergerak ke arah penutur atau perspektif penutur (sifatnya subjektif penutur), sementara te iku menyatakan sesuatu perubahan yang menjauh dari tempat penutur/perspektif penutur, atau ketika penutur melihat sesuatu (gerakan/perubahan) bergerak ke suatu arah secara objektif.

(24) Ninki ga agatte kuru.

Popular NOM naik datang (AUX) NPST

'(Mereka) akan menjadi popular (sejak sekarang).'

(25) Ninki ga agatte iku.

Popular NOM naik pergi (AUX) NPST

'(Mereka) akan menjadi popular (sejak sekarang).'

Perbedaan antara (24) dan (25) adalah masalah perspektif atau empati dari dari penuturnya. Pada (24) penutur menilai secara subjektif apa yang dirasakannya akan hal yang dituturkan, sementara pada (25) penutur secara objektif melihat kepopularan mereka. Penggunaan te kuru melibatkan emosi/empati penutur, berdasarkan apa yang dirasakan penutur. Contoh lain:

(26) Atsuku natte kuru. 
Panas ADV menjadi datang (AUX) NPST

'(Cuacanya) menjadi panas (dari sekarang).'

(27) Atsuku natte iku.

Panas ADV menjadi pergi (AUX) NPST

'(Cuacanya) menjadi panas (mulai dari sekarang).'

Pada (26) jika penutur merasakan sendiri panasnya cuaca, sementara pada (27) penutur menggambarkan secara objektif tentang perubahan cuaca.

(28) Yatto wakatte kita .

Akhirnya paham datang (AUX) PST

'Akhirnya (saya) paham sekarang.'

Pada (28) penutur menyatakan bahwa setelah selama kurun waktu tertentu tidak paham pada akhirnya (saat ia menuturkan) ia dapat memahaminya. Ini adalah tentang perubahan kondisi dari sebelumnya "tidak paham" menjadi "paham" ketika penutur bertutur.

\section{Deiksis wacana/tekstual dan deiksis sosial}

Dengan melihat paparan tentang ketiga deiksis sebelumnya, sebenarnya dalam bahasa Jepang sulit untuk dipisah-pisahkan di antara semuanya. Masing-masing saling terkait, keberadaan deiksis orang akan melibatkan deiksis sosial, demikian juga yang lainnya. Deiksis wacana dan sosial sebenarnya adalah kategori deiksis yang muncul belakangan. Deiksis wacana merupakan jenis deiksis yang rujukannya berada di dalam teks/wacana. Muncul dalam teks sebelum (anafora) maupun sesudah (katafora) ungkapan deiksis. Wujud deiksis wacana dapat berupa kata ganti orang (deiksis orang), kata ganti tempat (deiksis tempat), dan juga kata ganti demontratif ko, so, dan $a$.

Sementara untuk deiksis sosial penerapannya bergantung pada konteks sosial, yakni ungkapan deiksis yang rujukannya berdasarkan peran sosial partisipan pertuturannya. Pada bagian deiksis orang sudah dijelaskan secara detil fenomena penggunaan deiksis bahasa Jepang yang dapat dikatakan mendasarkan pada konteks sosial. Di dalam konteks sosial diidentifikasi hubungan sosial di antara para partisipannya. Apakah penutur dan mitra tutur atau pihak terlibat lainnya mempunyai hubungan kedekatan (uchi) atau tidak (soto), atau bagaimana perbedaan kedudukan di antara mereka (jogekankei).

Dalam bahasa Jepang, realisasi peran sosial dalam bahasa diatur dalam sistem yang disebut keigo (honorific). Sistem ini mengatur penggunaan bahasa berdasarkan peran sosialnya. 
Secara umum keigo dibagi menjadi tiga kategori, yakni sonkeigo, kenjogo, dan teineigo. Dua kategori yang pertama merupakan bahasa hormat yang didasarkan pada pelaku aktifitas dan kategori yang ketiga berhubungan dengan formalitas peristiwa dan mitra tutur atau audience. Sonkeigo adalah bahasa hormat yang digunakan untuk aktifitas yang dilakukan oleh orang lain (soto) yang mempunyai kedudukan lebih tinggi dibandingkan penutur, dan kenjogo merupakan bahasa hormat yang digunakan untuk menyatakan aktifitas penutur atau uchi terhadap mitra tutur yang kedudukannya lebih tinggi. Dalam istilah linguistik keduanya disebut referent honorifics, yakni honorific yang acuannya pelaku aktifitas, yang terdiri atas subject honorifics/SH (sonkeigo) dan object honorifics/OH (kenjogo). Sementara teineigo dalam istilah linguistik disebut addressee honorifics/AH.

a. Ashita irassha-imasu.

Besok datang SH-AH NPST

'Besok (beliau) akan datang'

b. Ashita mair-imasu.

Besok datang OH-AH NPST

'Besok (saya) akan datang.'

Meskipun dalam (29) a. dan b. subjeknya dilesapkan, namun dengan melihat verbanya dapat diketahui bahwa dalam a. pelaku adalah orang lain (soto) yang mempunyai kedudukan lebih tinggi dari penutur karena menggunakan sonkeigo. Sementara dalam b. yang verbanya menggunakan kenjogo menandakan pelaku adalah penutur atau uchi. Ini adalah salah satu contoh penggunaan deiksis sosial.

Penggunaan predikat atau verba yang menjadi deiksis sosial juga terjadi pada verba beri-terima. Verba ini mencakup:

- yaru 'memberi (kepada soto, status pemberi lebih tinggi atau sama/akrab) (NPOL)';

- $\quad$ ageru 'memberi (kepada soto, status pemberi sama atau lebih tinggi) (NPOL)';

- oageni naru 'memberi (kepada soto) (SH)';

- $\quad$ sashiageru 'memberi (kepada soto) $(\mathrm{OH})$ ';

- $\quad$ kureru 'memberi (dari soto kepada uchi) (NPOL)';

- $\quad$ kudasaru 'memberi (dari soto kepada uchi) (SH)';

- morau 'menerima (dari soto) (NPOL)';

- omorai ni naru 'menerima (dari soto) (SH)'; 
- itadaku 'menerima (dari soto) $(\mathrm{OH})$ ';

Penggunaan verba ageru dan kureru (juga berlaku dalam verba bantu ageru/ $k u r e r u$ ) berbeda fokus peran dan empati dari penuturnya.

(30) a. Tanaka ha Abe ni okane wo ageta. (fokus sentral pada subjek) Tanaka TOP Abe DAT uang ACC memberi NPOL PST

'Tanaka memberi Abe uang.'

b. Tanaka ha boku ni okane wo kureta. (fokus sentral pada dative)

Tanaka TOP Abe DAT uang ACC memberi NPOL PST

'Tanaka memberi saya uang. (Saya diberi uang Tanaka)'

Dalam (30) a. pola tersebut menitik beratkan pada aktifitas subjek, sementara dalam b. pada penerima, karena penggunaan verba kureru selalu menunjukkan bahwa penerimanya adalah penutur atau uchi dari penutur. Keadaan ini sekaligus menunjukkan letak empati dari penutur. Pada a. jika dilihat dari hubungan uchi-soto sebenarnya tidak menggambarkan mana yang lebih dekat antara Tanaka dan Abe. Meskipun penggunaan verba ageru selalu untuk soto, pihak pemberi belum tentu uchi. Verba ageru pihak penerima selalu soto dan kureru selalu uchi. Dari sudut pandang empati, maka dalam pola a. empati penutur lebih condong ke Tanaka karena diposisikan sebagai subjek.

Verba ageru digantikan dengan sashiageru jika pihak penerimanya adalah orang yang lebih tinggi kedudukannya dibanding pemberi. Jika pihak pemberi yang lebih tinggi kedudukannya (tetapi pemberi bukan penutur), maka verba ageru dapat digantikan dengan oageni naru.

(31) Abe ha Tanaka ni okane wo moratta. (fokus sentral pada subjek) Abe TOP Tanaka dari uang ACC menerima NPOL PST 'Abe menerima uang dari Tanaka.'

Secara semantik makna (30) a. dan (31) adalah sama, hanya berbeda pola pada pengisi subjeknya. Pola keduanya juga tidak menunjukkan siapa yang lebih dekat (uchi) antara pihak penerima dan pemberi. Namun secara empati, dalam (31) penutur condong ke Abe karena dijadikan subjek.

\section{Simpulan}

Dari hasil analisis yang sudah dipaparkan dalam tulisan ini, nampak bahwa untuk memahami makna dan penggunaan deiksis bahasa Jepang diperlukan pemahaman konteks, 
terutama konteks sosial dan psikologi (empati). Dengan demikian sebenarnya dapat dikatakan bahwa sentral permasalahan deiksis bahasa Jepang adalah deiksis sosial dan empati. Penggunaan deiksis orang, tempat, dan waktu selalu berkaitan dengan keduanya.

Tulisan ini juga dapat menyimpulkan kalau dalam bahasa Jepang ditemukan verba deiksis yang variasi maknanya beragam. Contoh dari deiksis ini adalah verba (dan verba bantu) kuru/iku dan verba beri-terima (yaru, ageru, kureru, morau, dsb.). Penggunaan verba kuru/ kuru dapat dimaknai sebagai sesuatu (gerakan, tindakan, perubahan) datang/bergerak ke arah penutur atau perspektif penutur (sifatnya subjektif penutur), dan iku/ te iku menyatakan sesuatu (gerak, tindakan, perubahan) menjauh dari tempat penutur/perspektif penutur, atau ketika penutur melihat sesuatu (gerakan/perubahan) bergerak ke suatu arah secara objektif. Sementara penggunaan deiksis verba beri-terima lebih bervariasi baik dari variasi verbanya, penggunaan, dan maknanya. Melalui tuturan beri-terima dapat diketahui siapa pemberi dan penerimanya, kedudukan sosial, dan perasaan emosionalnya.

\section{Referensi}

Fillmore, C. J. (1975). Lectures on Deixis 1971. Reproduced by the Indiana University Linguistics Club.

Hasegawa, Y. (2012). Deictic and anaphoric uses of the Japanese demonstratives ko-so-a. Journal of Japanese Linguistics, 28(1). https://doi.org/10.1515/jjl-2012-0105

Irgens, B. (2017). Person Deixis in Japanese and English - a Contrastive Functional Analysis. University of Bergen.

Kuno, S., \& Kaburaki, E. (1977). Empathy and syntax. Linguistic Inquiry, 8(4), 627-672.

Lebra, T. S., \& Lebra, W. P. (Eds.). (1976). Japanese Culture and Behavior. Honolulu: University of Hawaii Press. https://doi.org/10.2307/2383595

Leech, G. (2014). The Pragmatics of Politeness. New York: Oxford University Press. https://doi.org/10.1093/acprof:oso/9780195341386.001.0001

Levinson, S. C. (1983). Pragmatics. London: Cambridge University Press.

Lyons, J. (1977). Semantics 2. Cambridge: Cambridge University Press.

Saifudin, A. (2005). Faktor Sosial Budaya dan Kesopanan Orang Jepang dalam Pengungkapan Tindak Tutur Terima Kasih pada Skenario Drama Televisi Beautiful Life Karya Kitagawa Eriko. Universitas Indonesia. https://doi.org/10.13140/RG.2.2.13134.56643

Saifudin, A. (2006). Sapaan untuk Orang Pertama dan Orang Kedua dalam Bahasa Jepang. Majalah Ilmiah Dian, 5(3).

Saifudin, A. (2010). Analisis Pragmatik Variasi Kesantunan Tindak Tutur Terima Kasih Bahasa Jepang dalam Film Beautiful Life Karya Kitagawa Eriko. LITE, 6(2), 172-181.

Saifudin, A. (2018). Konteks dalam Studi Linguistik Pragmatik. Lite: Jurnal Bahasa, Sastra, Dan 
Budaya, 14(1), 108-117.

Shibatani, M. (1990). The languages of Japan. Cambridge: Cambridge University Press.

Wetzel, P. J. . (1988). Japanese Social Deixis and Discourse Phenomena. The Journal of the Association of Teachers of Japanese, 22(1), 7-27. 